\title{
Article
}

\section{Robaru, Mini Underwater Robot for Survey of Reactor}

\author{
Rafiuddin Syam ${ }^{1 *}$, Syaiful Bakhri ${ }^{2}$ and Azwar Hayat ${ }^{1}$, Faizal A Samman ${ }^{3}$, Hamdani Hamdani ${ }^{1}$ \\ 1 Dept. of Mechanical Eng., Universitas Hasanuddin; azwar.hayat@gmail.com (AH), \\ hamdani.mechanical@gmail.com (HH) \\ 2 Center for Nuclear Reactor Technology and Safety - National Nuclear Energy Agency- BATAN; \\ bakhrisy@batan.go.id \\ 3 Dept. of Electrical Eng., Universitas Hasanuddin; faizalas@unhas.ac.id \\ * Correspondence: rafiuddinsyam@gmail.com.com
}

\begin{abstract}
A nuclear reactor leak is undesirable and unpredictable occurrence in the plant of nuclear energy generation. For this reason, an accurate equipment is needed to inspect and supervise reactors. There are two kind of reactors for research and industry reactors, both of them are needed to inspect. Concern to inspection, regularly check is needed to ensure reactor conditions are always safe to operate. For that reason, an application of advanced technology for detecting leaks is priority. In this research, we are using underwater robot to be implemented. Using the robot is able to detect periodically, continuously with accurate reports to the operator or reactor supervisor. Furthermore, Underwater Robot namely Robaru, with 4 propellers equipped at the robot, Robaru can move on 3 axes $\mathrm{x}, \mathrm{y}$ and $\mathrm{z}$ and rotate. The use of cameras, as well as temperature measurements to obtain data when conducting inspections of the reactor. The survey method used is direct observation to detect leaks. The robot is at a certain distance by following a predetermined connection or path. The robot has successfully performed a good check with an accurate level of positioning accuracy.
\end{abstract}

Keywords: underwater robot; control system; reactor; survey

\section{Introduction}

Research on underwater robots is growing rapidly, starting from mini robots to control strategies. As shown in the following paragraph. A small robotic fish (SAPPA) was manufactured by (Zhao et.al, 2015) and its propulsive performance was evaluated. SAPPA was developed to swim in bodies of freshwater such as rivers, and was equipped with a small CMOS camera with a wide-angle lens in order to photograph live fish. Another researcher, propose control system prototyping of a remotely-operated vehicle (ROV) with a docking hoop (DH) to recover an autonomous underwater vehicle (AUV) named AUVDH using a combination of software tools allows the prototyping process to be unified (Lin et.al, 2015).

Furthermore, the coordination strategy is based on the schooling behavior of fish as biomimetic underwater robot also introduce by (McColgan et.al, 2016), which is a decentralized approach that allows multiple AUVs to be self-organizing. Such a strategy can be effectively utilized for large spatiotemporal data collection for oceanic monitoring and surveillance purposes. A validated mathematical model of the BAUV developed at the University of Glasgow, RoboSalmon, is used to represent the agents within a school formation. Control strategy can be found at (Syam, 2016) and other works (Onny et.al, 2017).

In this research. In an attempt to develop underwater robot mini, the present prototype was downsized in order to improve its performance and to do survey at mini reactor. The robot is 
equipped with a wide-angle CMOS camera in front of the robot as a head to allow it to take real time video. Its prototype using 4 propellers mounting at the robot.

\section{Underwater Robot, Material and Methods}

In this research, the underwater robot has a length of $32.5 \mathrm{~cm}$ with a diameter of $10 \mathrm{~cm}$ with a weight of $2.5 \mathrm{~kg}$, while the body material uses Polylactic Acid. The propeller waterproof brushless motor is mount at front side and the rear side of the robot. These two propellers are to provide lifting force for the robot. The others propellers are connected at left and right side of the main body of the robot, see Figure 1. A Lithium Polymer Battery $(400 \mathrm{mAh}, 18.5 \mathrm{~V})$ is used as the electric power source of the robot. The robot has a camera 2 Megapixel high-performance CMOS, analog HD output, up to 1080P resolution, true day/night, smart IR, up to 20m IR distance, switchable TVI/AHD/CVI/ CVBS mounted at the front side to take video and pictures and a USB interface to connect to a PC in order to check the images real time. The robot also, equipped with a 3 W LED lamp.

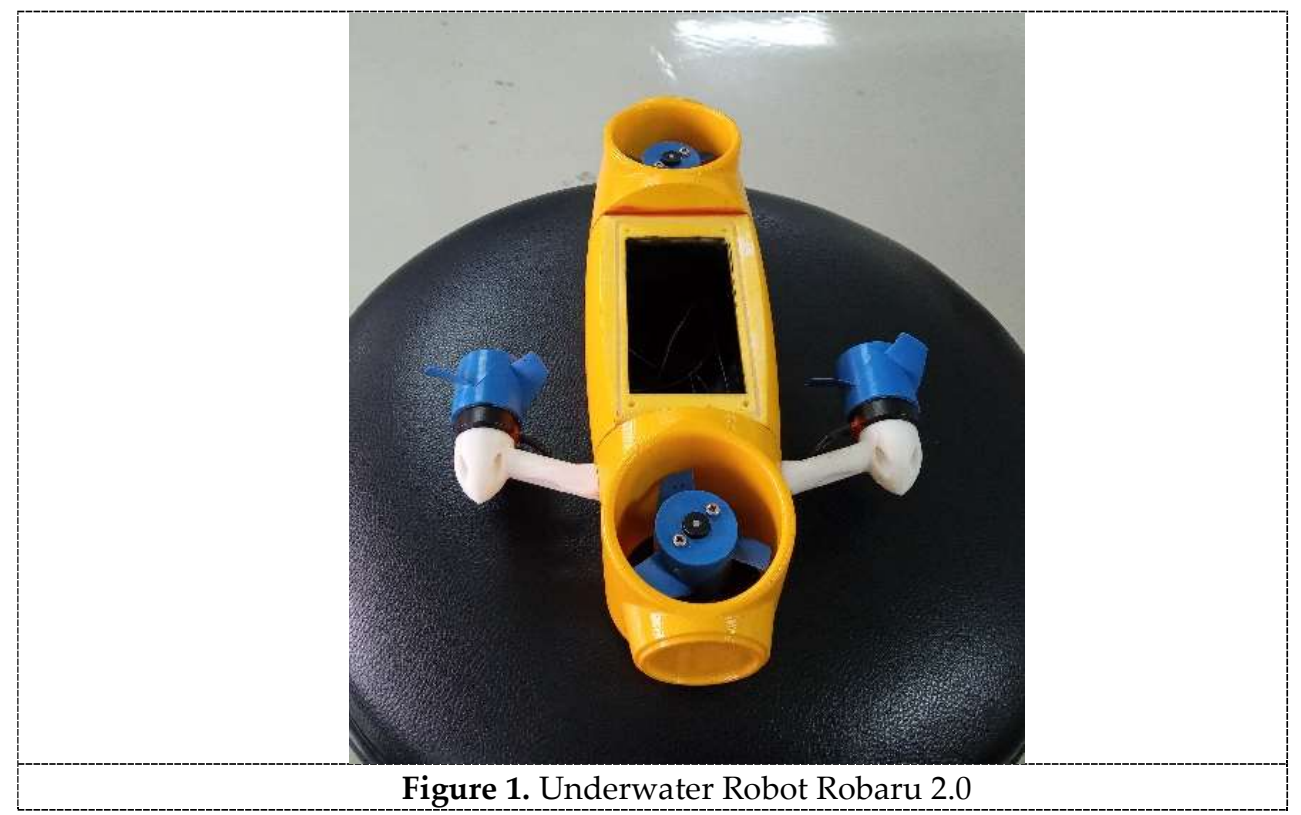

The Robaru 2.0 equipped temperature sensor chip with model DS18B20 and good sealing performance,ensuring his high sensitivity and minimal temperature delay. Its probe is made of highquality stainless steel. Effectively waterproof, moisture-proof and anti-rust, where the output lead: red (VCC), black (GND), yellow (DATA), with power supply range: $3.0 \mathrm{v}$ to $5.5 \mathrm{v}$ and Operating temperature range: $-55^{\circ} \mathrm{C}$ to $+125^{\circ} \mathrm{C}\left(-67^{\circ} \mathrm{F}\right.$ to $+257^{\circ} \mathrm{F}$, then the accuracy over the range of $-10^{\circ} \mathrm{C}$ to $+85^{\circ} \mathrm{C}: \pm 0.5^{\circ} \mathrm{C}$. 


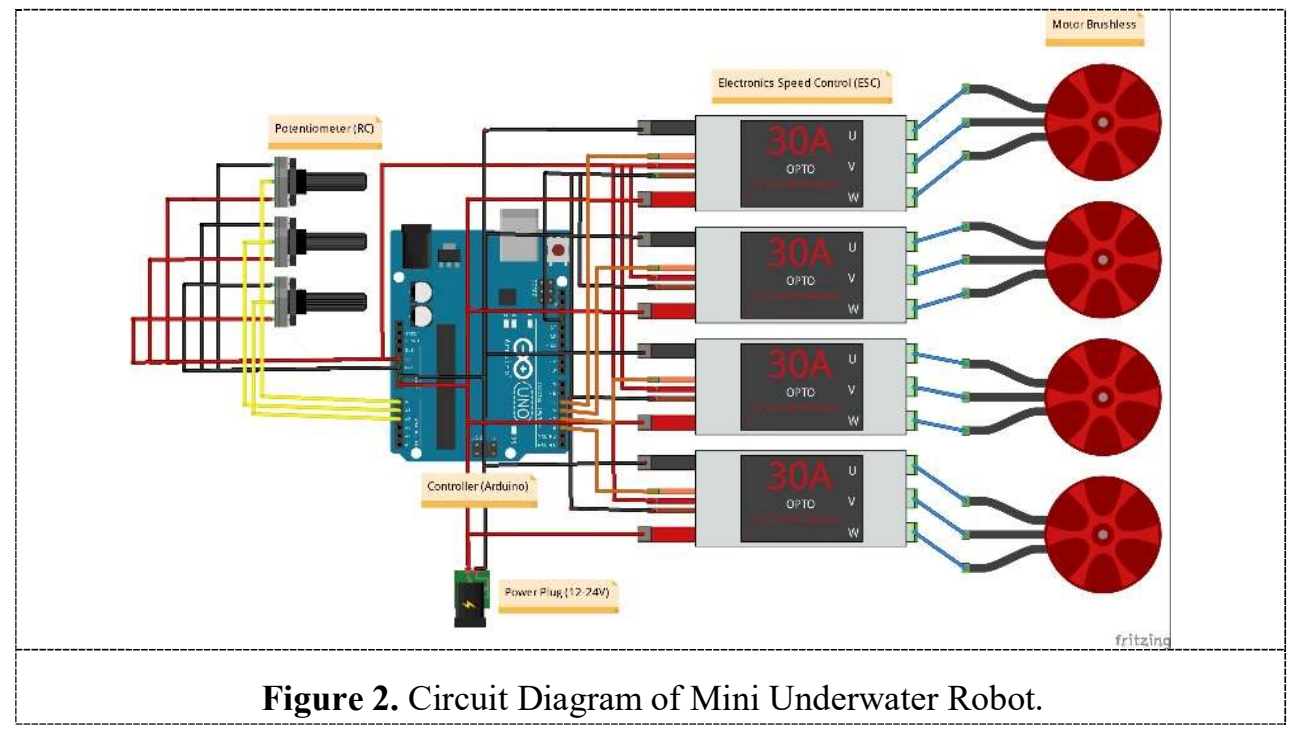

A circuit diagram of electronics system is shown in Figure 2. This robot uses an Arduino 101 Genuino microcontroller, Arduino shield, 4 ESC reverse support, voltage regulator. In figure 2, the Robaru microcontroller uses the Arduino 101 Genuino with the Intel Curie as its chip. The Arduino 101 is equipped with 14 digital input / output pins (4 of which can be used as PWM outputs), 6 analog inputs, a USB connector for serial communication and sketch upload, a power jack, an ICSP header with an SPI signal and an $\mathrm{I} 2 \mathrm{C}$ dedicated pin. The board operating voltage and $\mathrm{I} / \mathrm{O}$ is $3.3 \mathrm{~V}$ but all pins are protected from 5V overvoltages. Arduino 101 and Genuino 101 boards in collaboration with Intel Corp.

Then, a total of 3 potentiometers are used as command input for Robaru movement in the water which are all connected to the 3 analog pins of Arduino 101, then there are 4 ESCs (electronics speed control, Blue Robotics Inc, California, USA) connected to the Arduino 101 via 4 digital pins. In the movement of the robot itself, there are 4 waterproof $2838350 \mathrm{KV}$ brushless outrunner motors with $60 \mathrm{~mm}$ with a $2.4 \mathrm{KG}$ thrust propeller where the rotation is controlled by $4 \mathrm{ESC}$ each.

The command from the operator through the potentiometer is processed by Arduino 101 and then forwarded to the ESC until finally the ESC can turn the brushless motor.

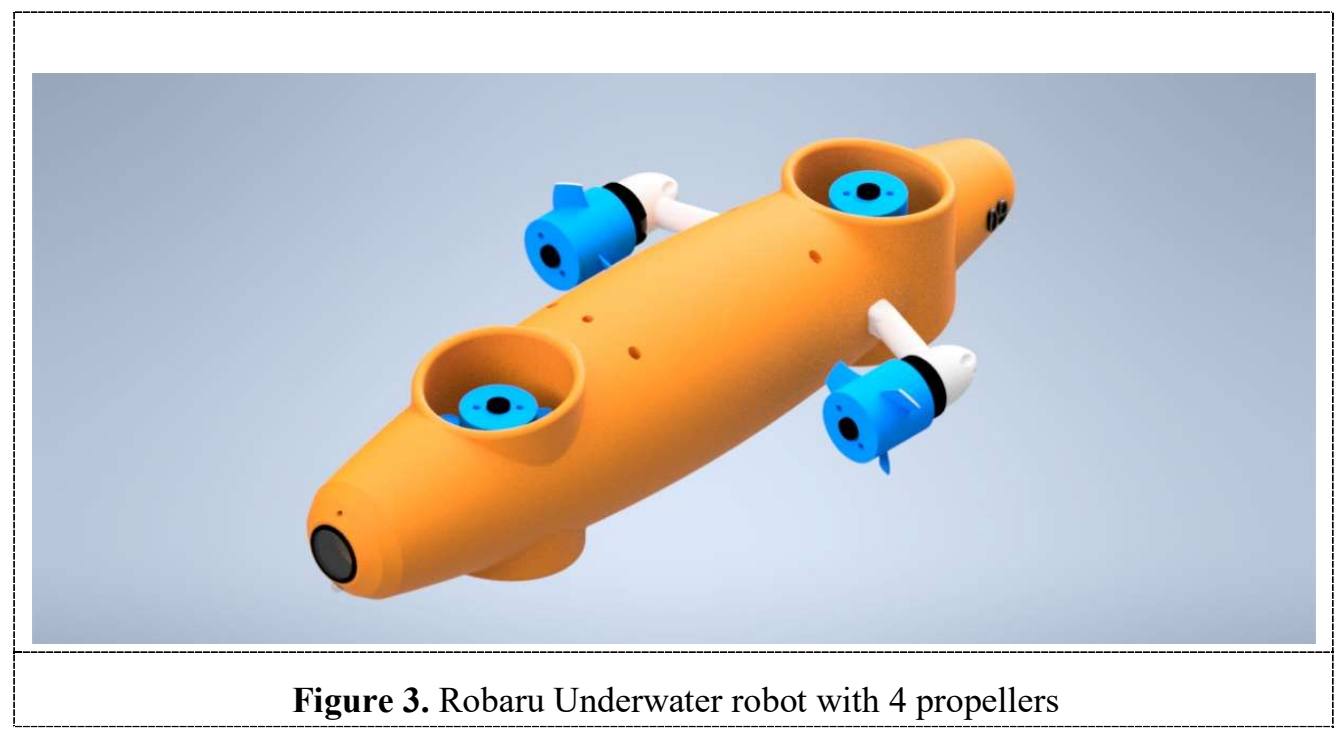


In the Figure 3 is shown perspective of underwater robot called Robaru with 4 propellers. A camera and LED $3 \mathrm{~W}$ are equipped at front side of Robaru. The body of robot underwater is compact with Polylactic Acid. The four propellers are waterproof brushless motor, where the first propeller is at the front and the second propeller is at the rear. Both propellers functions are for lifting the robot. While the propeller on the left and right functions to go forward and backward, turn left and right in the horizontal direction.

\section{Results}

Experiments were carried out with direct control. This robot track used is an observation in the vertical direction, namely the robot moves on the $x$-axis and the $y$-axis. Being on a constant $z$-axis. There is movement on the $z$-axis, but it is not considered an error trajectory.

\section{Conclusions}

In the present study, underwater robot Robaru 2.0 as inspection robot for reactor was developed. It already improves the performance of robot maneuver for inline in trajectory position. Robaru has 4 propellers brushless electric motor. It was designing the robot has a length of $32.5 \mathrm{~cm}$ with a diameter of $10 \mathrm{~cm}$ with a weight of $2.5 \mathrm{~kg}$, while the body material uses Polylactic Acid.

Acknowledgments: The authors would like to appreciate assistance from LPPM Unhas, BATAN Indonesia and gratitude to DGHE, Directorate General High Education, Republic of Indonesia and BRIN, Ministry Research and Technology, Republic of Indonesia for financial support.

\section{References}

1. Zhao, Y.; Fukuhara, M.; Usami, T.; Takada, Y., 2015, Performance of Very Small Robotic Fish Equipped with CMOS Camera. Robotics (ISSN 2218-6581), 4, 421-434.

2. Lin, W.P.; Chin, C.S.; Looi, L.C.W.; Lim, J.J.; Teh, E.M.E., 2015, Robust Design of Docking Hoop for Recovery of Autonomous Underwater Vehicle with Experimental Results. Robotics, 4, 492-515.

3. McColgan, J.; McGookin, E.W., 2016, Coordination of Multiple Biomimetic Autonomous Underwater Vehicles Using Strategies Based on the Schooling Behaviour of Fish. Robotics, 5, 2.

4. Syam, R., 2016, Dynamics and Fuzzy Logic Method for Controlling Quadcopter, Research Journal of Applied Sciences 11 (6), 251-260

5. Onny, S.; Syam, R.; Sapta, A.; 2017, Controlling Unmanned Surface Vehicle Rocket using GPS Tracking Method, International Journal of Technology, 8(4), 709-718. doi:10.14716/ijtech.v8i4 